\title{
A PROOF OF JACKSON'S THEOREM
}

\author{
BY R. BOJANIC AND R. DEVORE
}

Communicated by Eugene Isaacson, October 17, 1968

1. If $f$ is a continuous function on $[-1,1]$ and $\omega_{f}$ its modulus of continuity, then the classical theorem of Jackson [1] states that there exists a sequence of polynomials $\left(J_{n}[f]\right)$ such that the degree of $J_{n}[f]$ is $\leqq n$ and

$$
\max _{|x| \leqq 1}\left|J_{n}[f](x)-f(x)\right| \leqq C \omega_{f}\left(\frac{1}{n}\right), \quad n=1,2, \cdots .
$$

Various direct, but more or less involved proofs of this result are now available in the literature (see [2], [3], [4], [5], [6] and [7]). In [6] it was shown that Legendre polynomials generate approximating polynomials whose deviation from $f$ on $[-1 / 4,1 / 4]$ is of the order $\omega_{f}(1 / n)$, as in Jackson's theorem. In [7] this result was extended to a large class of orthogonal polynomials.

The aim of this paper is to give a short and simple direct proof of Jackson's theorem by combining an inequality for positive linear operators which was proved recently by O. Shisha and B. Mond [8], with the ideas developed in [6] and [7].

Let $T_{2 n}(x)=\cos (2 n$ arc $\cos x)$ be the Chebyshev polynomial of degree $2 n, \alpha_{n}=\sin (\pi / 4 n)$ its smallest positive zero and

$$
R_{n}(x)=c_{n}\left(\frac{T_{2 n}(x)}{x^{2}-\alpha_{n}^{2}}\right)^{2},
$$

where $c_{n}$ is chosen so that $\int_{-1}^{1} R_{n}(t) d t=1$. Also let

$$
\|g\|=\sup \{|g(x)|:|x| \leqq 1 / 4\} .
$$

We shall prove here the following theorem.

If $f$ is a continuous function on $[-1 / 2,1 / 2]$, then the polynomial $K_{n}[f]$ defined by

$$
K_{n}[f](x)=\int_{-1 / 2}^{1 / 2} f(t) R_{n}(t-x) d t
$$

satisfies the inequality

$$
\left\|K_{n}[f]-f\right\| \leqq 2 \omega_{f}\left(\frac{1}{n}\right)+16\|f\| \frac{1}{n^{2}}, \quad n=1,2, \cdots
$$


In order to obtain from (2) a proof of Jackson's theorem for the interval $[-1 / 4,1 / 4]$, it is sufficient to consider the modified polynomials $\bar{K}_{n}[f]$ defined by $\bar{K}_{n}[f]=f(0)+K_{n}[f-f(0)]$. Using (2) and elementary properties of the modulus of continuity, we find that for $n \geqq 3$

$$
\left\|\bar{K}_{n}[f]-f\right\| \leqq 2 \omega_{f}\left(\frac{1}{n}\right)+16 \omega_{f}\left(\frac{1}{4}\right) \frac{1}{n^{2}} \leqq 4 \omega_{f}\left(\frac{1}{n}\right) .
$$

2. In order to simplify the proof of the theorem, we shall first prove the following result.

Lemma. For $n=1,2, \cdots$ we have $\int_{-1}^{1} t^{2} R_{n}(t) d t \leqq 1 / n^{2}$.

Proof of the lemma. We have first

$$
\int_{-1}^{1} t^{2} R_{n}(t) d t \leqq \int_{-1}^{1}\left(1-t^{2}\right)^{-1 / 2} t^{2} R_{n}(t) d t .
$$

Next, by Gauss quadrature formula based on the zeros of $T_{2 n}$, we have for any polynomial $P$ of degree $\leqq 4 n-1$

$$
\int_{-1}^{1}\left(1-t^{2}\right)^{-1 / 2} P(t) d t=\frac{\pi}{2 n} \sum_{k=1}^{2 n} P\left(\cos \frac{2 k-1}{4 n} \pi\right)
$$

(see [9, p. 115]). Since $R_{n}$ is an even polynomial of degree $4 n-4$, vanishing at all zeros of $T_{2 n}$ except at $\alpha_{n}$ and $-\alpha_{n}$, it follows that

$$
\begin{aligned}
\int_{-1}^{1}\left(1-t^{2}\right)^{-1 / 2} t^{2} R_{n}(t) d t & =\frac{\pi}{n} \alpha_{n}^{2} R_{n}\left(\alpha_{n}\right) \\
& =\alpha_{n}^{2} \int_{-1}^{1}\left(1-t^{2}\right)^{-1 / 2} R_{n}(t) d t \\
& =\alpha_{n}^{2} \int_{-1}^{1}\left(1-t^{2}\right)^{1 / 2} R_{n}(t) d t \\
& +\alpha_{n}^{2} \int_{-1}^{1}\left(1-t^{2}\right)^{-1 / 2} t^{2} R_{n}(t) d t
\end{aligned}
$$

i.e.,

$$
\left(1-\alpha_{n}^{2}\right) \int_{-1}^{1}\left(1-t^{2}\right)^{-1 / 2} t^{2} R_{n}(t) d t=\alpha_{n}^{2} \int_{-1}^{1}\left(1-t^{2}\right)^{1 / 2} R_{n}(t) d t .
$$

Since $\int_{-1}^{1} R_{n}(t) d t=1$ and $\alpha_{n}=\sin (\pi / 4 n)$, it follows that 


$$
\int_{-1}^{1}\left(1-t^{2}\right)^{-1 / 2} t^{2} R_{n}(t) d t \leqq \tan ^{2}(\pi / 4 n) \leqq 1 / n^{2}
$$

and the lemma is proved in view of the inequality (3).

PROOF OF THE THEOREM. The operator $K_{n}$ defined by (1) is clearly a positive linear operator. The inequality of Shisha and Mond mentioned earlier states that

$$
\left\|K_{n}[f]-f\right\| \leqq\left(1+\left\|K_{n}[1]\right\|\right) \omega_{f}\left(\mu_{n}\right)+\|f\| \cdot\left\|K_{n}[1]-1\right\|
$$

where $\mu_{n}=\left\|K_{n}\left[(t-x)^{2}\right](x)\right\|^{1 / 2}$. Here, the operator $K_{n}$ is applied to the variable $t \in[-1 / 2,1 / 2]$, while the sup norm \|\| is taken with respect to the variable $x \in[-1 / 4,1 / 4]$ (see $[8$, Theorem 1]). Hence, we have only to evaluate $\mu_{n},\left\|K_{n}[1]-1\right\|$ and $\left\|K_{n}[1]\right\|$.

We have, first, for $|x| \leqq 1 / 4$

$$
K_{n}\left[(t-x)^{2}\right](x)=\int_{-1 / 2}^{1 / 2}(t-x)^{2} R_{n}(t-x) d t \leqq \int_{-1}^{1} t^{2} R_{n}(t) d t
$$

and so by the lemma

$$
\stackrel{2}{\mu_{n}} \leqq \int_{-1}^{1} t^{2} R_{n}(t) d t \leqq 1 / n^{2} .
$$

Next,

$$
\begin{aligned}
1-K_{n}[1](x) & =\int_{-1}^{1} R_{n}(t) d t-\int_{-1 / 2}^{1 / 2} R_{n}(t-x) d t \\
& =\int_{-x+1 / 2}^{1} R_{n}(t) d t+\int_{-1}^{-x-1 / 2} R_{n}(t) d t .
\end{aligned}
$$

Hence, for $|x| \leqq 1 / 4$ we have

$$
\begin{aligned}
\left|1-K_{n}[1](x)\right| & \leqq\left(\int_{1 / 4}^{1}+\int_{-1}^{-1 / 4}\right) R_{n}(t) d t \\
& \leqq 16\left(\int_{1 / 4}^{1}+\int_{-1}^{-1 / 4}\right) t^{2} R_{n}(t) d t
\end{aligned}
$$

and so again by the lemma

$$
\left\|1-K_{n}[1]\right\| \leqq 16 \int_{-1}^{1} t^{2} R_{n}(t) d t \leqq 16 / n^{2} .
$$


Finally, for $|x| \leqq 1 / 4$

$$
K_{n}[1](x) \leqq \int_{-1}^{1} R_{n}(t) d t=1
$$

and (2) follows from (4), (5), (6) and (7).

\section{REFERENCES}

1. D. Jackson, The theory of approximation, Amer. Math. Soc. Colloq. Publ., vol. 11, Amer. Math. Soc., Providence, R. I., 1930.

2. V. K. Dzjadik, On the approximation of functions by algebraic polynomials on a finite interval of the real line, Izv. Akad. Nauk SSSR Ser. Mat. 22 (1958), 337-354. (Russian)

3. G. Freud, "Über ein Jacksonsches Interpolationsverfahren" in On approximation theory (Proceedings of the Conference in Oberwolfach, 1963), Birkhäuser, Basel, 1964.

4. R. B. Saxena, On a polynomial of interpolation, Studia Sci. Math. Hungar. 2 (1967), 167-183.

5. M. Sallay, Über ein Interpolationsverfahren, Magyar Tud. Akad. Mat. Kutat6 Int. Közl. 9 (1964-65), 607-615.

6. R. DeVore, On Jackson's theorem, J. Approximation Theory 1(1968), 314-318.

7. R. Bojanic, $A$ note on the degree of approximation to continuous functions, L'Enseignement Mathématique (to appear).

8. $O$. Shisha and B. Mond, The degree of convergence of sequences of linear positive operators, Proc. Nat. Acad. Sci. USA 60 (1968), 1196-1200.

9. V. I. Krylov, Approximate calculation of integrals, Macmillan, New York, 1962.

Ohio State University, Columbus, Ohio 43210 and

OAKLANd University, Rochester, Michigan 48063 